\title{
Microstructural Characterization of As-cast Hf-B Alloys
}

\author{
João Carlos Jânio Gigolottia, ${ }^{\mathrm{a} * *}$, Paulo Atsushi Suzuki, \\ Carlos Angelo Nunes ${ }^{\mathrm{a}}$, Gilberto Carvalho Coelho ${ }^{\mathrm{a}, \mathrm{b}}$
}

\begin{abstract}
a Departamento de Engenharia de Materiais - DEMAR, Escola de Engenharia de Lorena - EEL, Universidade de São Paulo - USP, CP 116, CEP 12600-970, Lorena, SP, Brazil

${ }^{b}$ Núcleo de Pesquisa, Centro Universitário de Volta Redonda - UniFoa, Campus Três Poços,

Av. Paulo Erlei Alves Abrantes, 1325, Três Poços, CEP 27240-560, Volta Redonda, RJ, Brazil
\end{abstract}

Received: November 28, 2010; Revised: December 2, 2011

An accurate knowledge of several metal-boron phase diagrams is important to evaluation of higher order systems such as metal-silicon-boron ternaries. The refinement and reassessment of phase diagram data is a continuous work, thus the reevaluation of metal-boron systems provides the possibility to confirm previous data from an investigation using higher purity materials and better analytical techniques. This work presents results of rigorous microstructural characterization of as-cast hafnium-boron alloys which are significant to assess the liquid composition associated to most of the invariant reactions of this system. Alloys were prepared by arc melting high purity hafnium (minimum 99.8\%) and boron (minimum 99.5\%) slices under argon atmosphere in water-cooled copper crucible with non consumable tungsten electrode and titanium getter. The phases were identified by scanning electron microscopy, using back-scattered electron image mode and X-ray diffraction. In general, a good agreement was found between our data and those from the currently accepted Hafnium-Boron phase diagram. The phases identified are $\alpha \mathrm{Hf}_{\mathrm{SS}}$ and B-Rhom $\mathrm{SS}_{\mathrm{sS}}$, the intermediate compounds $\mathrm{HfB}$ and $\mathrm{HfB}_{2}$ and the liquide $\mathrm{L}$. The reactions are the eutectic $\mathrm{L} \Leftrightarrow \alpha \mathrm{Hf}_{\mathrm{SS}}+\mathrm{HfB}$ and $\mathrm{L} \Leftrightarrow \mathrm{HfB}_{2}+\mathrm{B}-\mathrm{Rhom}$, the peritectic $\mathrm{L}+\mathrm{HfB}_{2} \Leftrightarrow \mathrm{HfB}$ and the congruent formation of $\mathrm{HfB}_{2}$.

Keywords: Hafnium-Boron, phase diagram, borides

\section{Introduction}

Metal-silicon-boron (Me-Si-B) alloys have been intensively studied due to their potential for the development of high temperature structural materials ${ }^{1-5}$. Considering that these materials are highly demanded in service, multicomponent based alloys seems to be the only possibility to satisfy all the requirements for structural integrity $^{6}$. In this sense, phase diagram information becomes extremely important. We have investigated several Me-Si-B systems from the point of view of phase stability and, as part of this work, the evaluation of binaries metal-silicon (Me$\mathrm{Si}$ ) and metal-boron (Me-B) became necessary. We have verified inconsistencies in binary systems such as $\mathrm{Nb}-\mathrm{B}^{7}$, $\mathrm{V}-\mathrm{B}^{8}$ and $\mathrm{Ta}-\mathrm{B}^{9}$, what demonstrates that the refinement and reassessment of phase diagram data is a continuous work. In this investigation, the microstructural characterization of as-cast (AC) hafnium-boron (Hf-B) alloys has been carried out. Revisiting the Hf-B system provides the opportunity to confirm previous data from an investigation using higher purity materials and better analytical techniques. Among other issues, it contributes to understand the solidification pathway of more complexes hafnium-silicon-boron (Hf$\mathrm{Si}-\mathrm{B}$ ) alloys, helping the goal of establishing the liquidus projection of this ternary system.

*e-mail: carlosjanio@uol.com.br
The currently accepted Hf-B phase diagram, from the work of Rudy and Windisch ${ }^{10}$, based on results of XRD analysis by means of Debye-Scherrer photographs and metallography of the samples, is shown in Figure 1. This diagram indicates the stability of the phases $\beta \mathrm{Hf}$ bodycentered cubic (BCC), $\alpha \mathrm{Hf}$ hexagonal compact (HCP), rhomboedric boron (B-Rhom) and liquid (L), as well as the intermediate phases $\mathrm{HfB}$ and $\mathrm{HfB}_{2}$.

Rogl and Potter ${ }^{11}$ assessmed the Hf-B system based on the experimental results of Rudy and Windisch ${ }^{10}$ and Portnoi and Romashov ${ }^{12,13}$. Bitterman and Rogl ${ }^{14}$ repeated the same assessment into the study of the Hf-B-C ternary system. Table 1 shows the proposals of Rudy and Windisch ${ }^{10}$, Rogl and Potter ${ }^{11}$, Portnoi and Romashov ${ }^{12}$ and Bitterman and Rogl $1^{14}$ for the reactions in the Hf-B system.

\section{Experimental Procedure}

Samples with compositions in all extension of the Hf-B diagram, 19 in total, were prepared. Pieces of $\mathrm{Hf}$ (minimum $99.8 \%$ ) and B (minimum 99.5\%) were arc-melted under argon atmosphere in water-cooled copper crucible with nonconsumable tungsten electrode and titanium getter to remove residual $\mathrm{O}_{2} / \mathrm{H}_{2} \mathrm{O} / \mathrm{N}_{2}$. Each alloy was melted three times in an effort to produce homogeneous ingots of 3-4 g. It has 


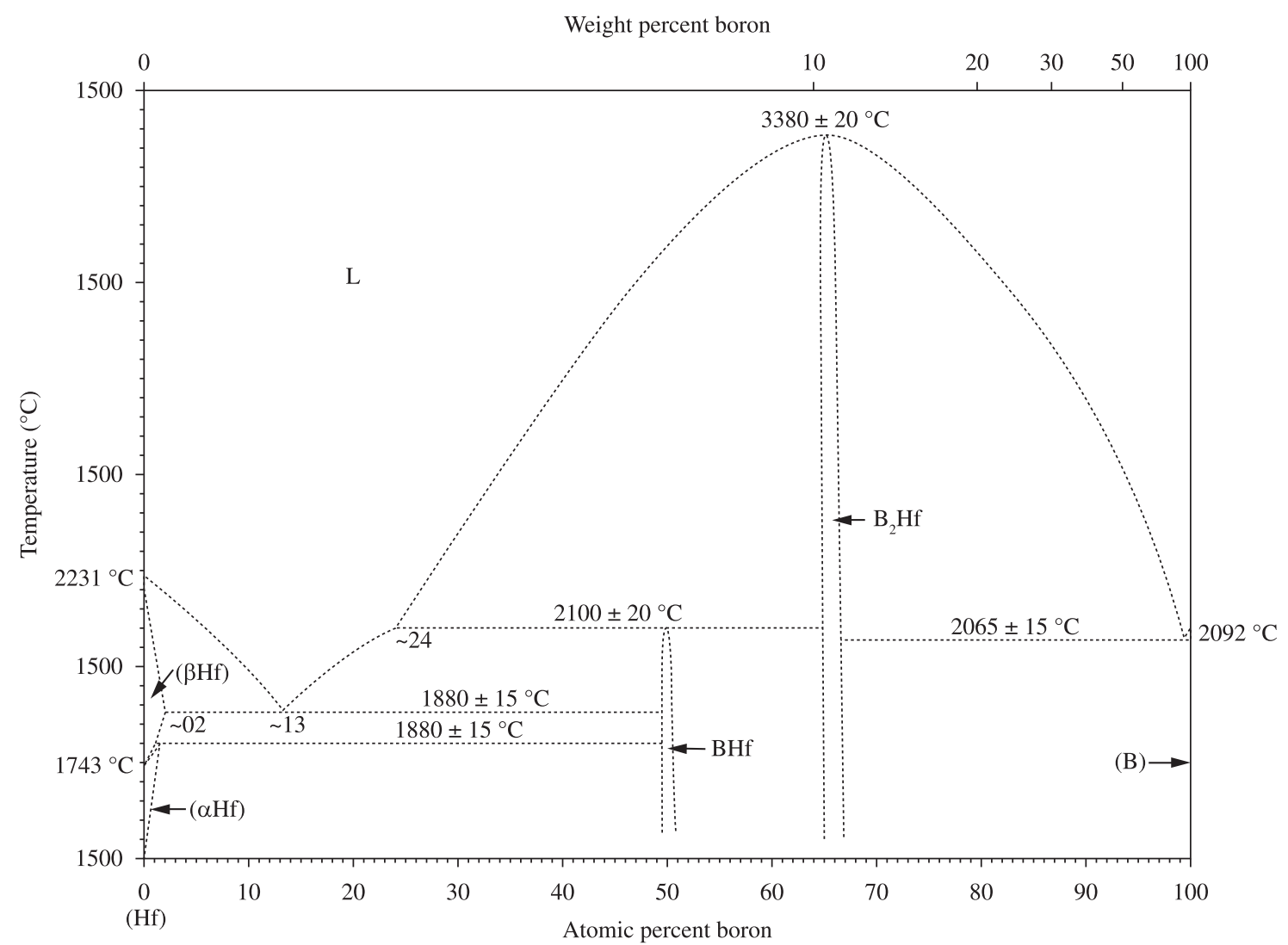

Figure 1. Hf-B Phase Diagram proposed by Rudy and Windisch ${ }^{10}$.

Table 1. Proposals of Rudy and Windisch ${ }^{10}$, Rogl and Potter ${ }^{11}$, Portnoi and Romashov ${ }^{12}$ Bitterman and Rog $1^{14}$ for the reactions in the Hf-B system.

\begin{tabular}{|c|c|c|c|c|c|c|}
\hline Reaction & \multicolumn{3}{|c|}{ Composition (\% at. B) } & Temperature $\left({ }^{\circ} \mathbf{C}\right)$ & Reference & Remarks \\
\hline \multirow[t]{4}{*}{$\mathrm{L} \Leftrightarrow \beta \mathrm{Hf}$} & \multicolumn{3}{|c|}{0} & 2231 & 10 & Experimental \\
\hline & \multicolumn{3}{|c|}{0} & 2220 & 12 & \\
\hline & \multicolumn{3}{|c|}{0} & 2231 & 11 & Calculated \\
\hline & \multicolumn{3}{|c|}{0} & 2233 & 14 & \\
\hline \multirow[t]{4}{*}{$\beta \mathrm{Hf} \Leftrightarrow \alpha \mathrm{Hf}$} & \multicolumn{3}{|c|}{0} & 1743 & 10 & Experimental \\
\hline & \multicolumn{3}{|c|}{0} & 1780 & 12 & \\
\hline & \multicolumn{3}{|c|}{0} & $\sim 1780$ & 11 & Calculated \\
\hline & \multicolumn{3}{|c|}{0} & 1743 & 14 & \\
\hline \multirow{3}{*}{$\beta \mathrm{Hf}_{\mathrm{ss}}+\mathrm{HfB} \Leftrightarrow \alpha \mathrm{Hf}_{\mathrm{ss}}$} & $<02$ & 50 & $<02$ & $1800+15$ & 10 & Experimental \\
\hline & $<0.5$ & 50 & $<0.50$ & $2073 \pm 15$ & 11 & Calculated \\
\hline & 0.70 & 50 & 1.50 & 1791 & 14 & \\
\hline \multirow{4}{*}{$\begin{array}{c}\beta \mathrm{Hf}_{\mathrm{sS}}+\mathrm{HfB}_{2} \Leftrightarrow \alpha \mathrm{Hf}_{\mathrm{sS}} \\
\mathrm{L} \Leftrightarrow \alpha \mathrm{Hf}_{\mathrm{sS}}+\mathrm{HfB}\end{array}$} & 02 & 66.67 & 02 & $1800 \pm 15$ & 12 & Experimental \\
\hline & $\sim 13$ & $\sim 02$ & 50 & $1880 \pm 15$ & 10 & Experimental \\
\hline & 14.40 & 2 & 50 & 1874,70 & 11 & Calculated \\
\hline & 15 & 1.10 & 50 & 1881 & 14 & \\
\hline \multirow{4}{*}{$\begin{array}{c}\mathrm{L} \Leftrightarrow \alpha \mathrm{Hf}_{\mathrm{sS}}+\mathrm{HfB}_{2} \\
\mathrm{~L}+\mathrm{HfB}_{2} \Leftrightarrow \mathrm{HfB}\end{array}$} & $\sim 11$ & $\sim 02$ & $\sim 66.67$ & 1820 & 12 & Experimental \\
\hline & $\sim 24$ & 66.67 & 50 & $2100 \pm 20$ & 10 & Experimental \\
\hline & 22.50 & 66.70 & 50 & 2098.70 & 11 & Calculated \\
\hline & 22 & 66.70 & 50 & 2104 & 14 & Calculated \\
\hline \multirow[t]{4}{*}{$\mathrm{L} \Leftrightarrow \mathrm{HfB}_{2}$} & & 66.67 & & $3380 \pm 20$ & 10 & Experimental \\
\hline & & 66.67 & & 3330 & 12 & \\
\hline & & 66.67 & & 3380.90 & 11 & Calculated \\
\hline & & 66.67 & & 3377 & 14 & \\
\hline
\end{tabular}


Table 1. Continued...

\begin{tabular}{|c|c|c|c|c|c|c|}
\hline \multirow{2}{*}{$\frac{\text { Reaction }}{\mathrm{L} \Leftrightarrow \mathrm{HfB}_{2}+\beta \mathrm{B}-\mathrm{Rhom}}$} & \multicolumn{3}{|c|}{ Composition (\% at. B) } & \multirow{2}{*}{$\frac{\text { Temperature }\left({ }^{\circ} \mathbf{C}\right)}{2065 \pm 15}$} & \multirow{2}{*}{$\frac{\text { Reference }}{10}$} & \multirow{2}{*}{$\begin{array}{c}\text { Remarks } \\
\text { Experimental }\end{array}$} \\
\hline & $\sim 99$ & 66.67 & 100 & & & \\
\hline & $\sim 99$ & 66.67 & 100 & 2065 & 12 & \\
\hline & 97.30 & 66.70 & $\sim 98$ & 2065 & 11 & Calculated \\
\hline & 99 & 66.70 & 100 & 2065 & 14 & \\
\hline \multirow[t]{4}{*}{$\mathrm{L} \Leftrightarrow \beta \mathrm{B}-\mathrm{Rhom}$} & & 100 & & 2092 & 10 & Experimental \\
\hline & & 100 & & 2170 & 12 & \\
\hline & & 100 & & 2092 & 11 & Calculated \\
\hline & & 100 & & 2075 & 14 & \\
\hline $\mathrm{HfB}+\mathrm{HfB}_{2} \Leftrightarrow \mathrm{Hf}_{3} \mathrm{~B}_{4}$ & 50 & 66.70 & 42.85 & 435.60 & 11 & Calculated \\
\hline $\mathrm{HfB}_{2}+\beta \mathrm{B}-$ Rhom $\Leftrightarrow \mathrm{HfB}_{12}$ & 66.70 & $\sim 98$ & 92.31 & 2058 & 11 & \\
\hline
\end{tabular}

Table 2. Crystalographic data of the phases of the Hf-B system.

\begin{tabular}{|c|c|c|c|c|c|c|c|c|c|c|}
\hline \multirow[t]{2}{*}{ Phase } & \multirow{2}{*}{$\begin{array}{l}\text { Structure } \\
\text { type }\end{array}$} & \multirow{2}{*}{$\begin{array}{l}\text { Space } \\
\text { group }\end{array}$} & \multirow{2}{*}{$\begin{array}{c}\text { Pearson } \\
\text { symbol }\end{array}$} & \multirow{2}{*}{$\begin{array}{l}\text { Wyckhoff } \\
\text { position }\end{array}$} & \multirow[t]{2}{*}{ Simetry } & \multirow[t]{2}{*}{ Occupation } & $\mathbf{x}$ & $\mathbf{y}$ & $\mathbf{z}$ & \multirow[t]{2}{*}{ Ref. } \\
\hline & & & & & & & $\mathbf{a}(\AA)$ & b (̊̊) & c (̊̊) & \\
\hline \multirow[t]{2}{*}{$\beta \mathrm{Hf}$} & W & $\operatorname{Im} 3 \mathrm{~m}$ & $\mathrm{cI} 2$ & $2 \mathrm{a}$ & $\mathrm{m} 3 \mathrm{~m}$ & $\mathrm{Hf}$ & 0 & 0 & 0 & 16,17 \\
\hline & & & & & & & 3.2260 & & & \\
\hline \multirow[t]{2}{*}{$\alpha \mathrm{Hf}$} & $\mathrm{Mg}$ & $\mathrm{P}_{3} / \mathrm{mmc}$ & hP2 & $2 \mathrm{c}$ & $6 \mathrm{~m} 2$ & $\mathrm{Hf}$ & 0.33330 & 0.66670 & 0.25000 & 17,18 \\
\hline & & & & & & & 3.1980 & & 5.0610 & \\
\hline \multirow[t]{3}{*}{ HfB } & $\mathrm{FeB}$ & Pnma & oP8 & $4 \mathrm{c}$ &. $\mathrm{m}$ & B & 0.03600 & 0.25000 & 0.61000 & 19 \\
\hline & & & & $4 c$ &. $\mathrm{~m}$ & $\mathrm{Hf}$ & 0.18000 & 0.25000 & 0.12500 & \\
\hline & & & & & & & 6.5185 & 3.2160 & 4.9190 & \\
\hline \multirow[t]{3}{*}{$\mathrm{HfB}_{2}$} & $\mathrm{AlB}_{2}$ & $\mathrm{P} 6 / \mathrm{mmm}$ & hP3 & $1 \mathrm{a}$ & $6 / \mathrm{mmm}$ & $\mathrm{Hf}$ & 0 & 0 & 0 & 17,20 \\
\hline & & & & $2 \mathrm{~d}$ & $6 \mathrm{~m} 2$ & B & 0.33330 & 0.66670 & 0.50000 & \\
\hline & & & & & & & 3.1390 & & 3.4730 & \\
\hline \multirow[t]{18}{*}{ B-Rhom } & B & $\mathrm{R}-3 \mathrm{mh}$ & hR423 & $36 \mathrm{i}$ & 1 & B & 0.00203 & 0.17779 & 0.32317 & 21 \\
\hline & & & & $36 \mathrm{i}$ & 1 & B & 0.01424 & 0.37071 & 0.03783 & \\
\hline & & & & $36 \mathrm{i}$ & 1 & B & 0.04431 & 0.26123 & 0.08013 & \\
\hline & & & & $36 \mathrm{i}$ & 1 & B & 0.25163 & 0.01528 & 0.15315 & \\
\hline & & & & $18 \mathrm{~h}$ &.$m$ & B & 0.38876 & 0.61124 & 0.11076 & \\
\hline & & & & $18 \mathrm{~h}$ &. $\mathrm{~m}$ & B & 0.41969 & 0.58032 & 0.17999 & \\
\hline & & & & $18 \mathrm{~h}$ &.$m$ & B & 0.44408 & 0.55592 & 0.05327 & \\
\hline & & & & $18 \mathrm{~h}$ &.$m$ & B & 0.50326 & 0.49674 & 0.19449 & \\
\hline & & & & $18 \mathrm{~h}$ & .m & B & 0.53676 & 0.46323 & 0.06706 & \\
\hline & & & & $18 \mathrm{~h}$ &.$m$ & $\mathrm{Cr}$ & 0.53881 & 0.46120 & 0.34031 & \\
\hline & & & & $18 \mathrm{~h}$ &.$m$ & B & 0.56428 & 0.43571 & 0.13520 & \\
\hline & & & & $18 \mathrm{~h}$ &.$m$ & B & 0.61025 & 0.38975 & 0.27838 & \\
\hline & & & & $18 \mathrm{~h}$ &.$m$ & B & 0.72309 & 0.27692 & 0.16006 & \\
\hline & & & & $18 \mathrm{~h}$ &.$m$ & B & 0.75685 & 0.24315 & 0.23192 & \\
\hline & & & & $6 c$ & $3 m$ & B & 0 & 0 & 0.11483 & \\
\hline & & & & $6 c$ & $3 \mathrm{~m}$ & $\mathrm{Cr}$ & 0 & 0 & 0.36549 & \\
\hline & & & & $3 a$ & $-3 m$ & B & 0 & 0 & 0 & \\
\hline & & & & & & & 10.9637 & & 23.8477 & \\
\hline
\end{tabular}

been calculated the composition interval for each alloy from the mass losses associated to the melting steps, supposing that all mass losses were either from Hf or B volatilization. The composition adopted for each alloy is expressed by the mean value of this interval. The alloys were characterized via scanning electron microscope in the back-scattered electron mode, and X-ray diffraction were performed in a
Shimadzu XRD6000 diffractometer, at room temperature, with $\mathrm{CuK} \alpha$ radiation and graphite monochromator. For the analysis via scanning electron microscope, the alloys were prepared following standard metallographic procedures: hot mounting in resin; grinding in the sequence \#220-\#4000 with SiC paper; and polishing with colloidal silica suspension (OP-S). The images were obtained in a LEO 1450VP 
instrument. For the X-ray diffraction experiment the samples were mechanically ground and sieved to below $80 \mathrm{mesh}$. The measurement conditions were: $10^{\circ}<2 \theta 90^{\circ} ; 0.05^{\circ}(2 \theta$ step) and 2 seconds integration time. The phases in each sample were identified based on the simulated diffractions patterns obtained from the program PowderCell for Windows ${ }^{\circledR}$ (version 2.3$)^{15}$ using crystallographic data shown in Table 2.

\section{Results and Discussion}

Table 3 shows the phases present in each alloy as well as the type of invariant reaction observed in each microstructure.

The Figure 2 shows $\mathrm{X}$-ray diffractograms and the Figure 3 the micrographs of the Hf88B12 (a), Hf77B23 (b), Hf75B25 (c), Hf50B50 (d), Hf33,4B66,6 (e), Hf7,7B92,3 (f) and Hf01B99 (g) in the as-cast condition.

The alloy with composition 12 at.\% B intended to verify the composition of the liquid in the eutectic transformation $\mathrm{L} \Leftrightarrow \alpha \mathrm{Hf}_{\mathrm{sS}}+\mathrm{HfB}$ in Hf-rich region, as proposed by Rudy and Windisch ${ }^{10}$. The diffractogram of the Hf88B12 alloy (Figure 2a) has indicated the presence of $\alpha \mathrm{Hf}$ solid solution $\left(\alpha \mathrm{Hf}_{\mathrm{sS}}\right)$ and HfB phases while the micrograph of this alloy (Figure 3a) shows essentially a typical eutectic microstructure composed of $\alpha \mathrm{Hf}_{\mathrm{sS}}$ and HfB phases, which confirms the Rudy and Windisch's proposal ${ }^{10}$ (Figure 1) for the composition of the liquid that participates of the reaction $\mathrm{L} \Leftrightarrow \alpha \mathrm{Hf}_{\mathrm{SS}}+\mathrm{HfB}$ at approximately 13 at. $\% \mathrm{~B}$, close to the composition calculated by Rogl and Potter ${ }^{11}$ and Bitterman and $\operatorname{Rogl}^{14}$, respectively, at 14.4 at.\% B and 15 at.\% B.

The alloys with compositions between 20 at.\% B and 50 at. $\% \mathrm{~B}$ intended to verify the composition of the liquid in the peritetic transformation $\mathrm{L}+\mathrm{HfB}_{2} \Leftrightarrow \mathrm{HfB}$, as proposed by Rudy and Windisch ${ }^{10}$. The diffractogram of the Hf77B23 alloy (Figure 2b) has indicated the presence of $\alpha \mathrm{Hf}_{\mathrm{sS}}$ and $\mathrm{HfB}$ phases. It is noted a relative increase in the intensity of the HfB peaks compared to the previous alloy. The micrograph of this alloy (Figure $3 b$ ) indicates primary precipitation of $\mathrm{HfB}$ and the $\alpha \mathrm{Hf}_{\mathrm{SS}}+\mathrm{HfB}$ eutectic microstructure in the remaining region, in agreement with the previous result.

The diffractograms of the Hf75B25 (Figure 2c) and Hf50B50 (Figure 2d) alloys have indicated the presence of $\alpha \mathrm{Hf}_{\mathrm{SS}}, \mathrm{HfB}$ and $\mathrm{HfB}_{2}$ phases. In the microstructure of the Hf75B25 alloy (Figure 3c), precipitation of HfB is observed with a typical $\alpha \mathrm{Hf}_{\mathrm{ss}}+\mathrm{HfB}$ eutectic microstructure in the

Table 3. Alloy compositions, identified phases in each alloy and type of invariant reaction observed.

\begin{tabular}{ccl}
\hline $\begin{array}{c}\text { Composition } \\
\text { (at.\%) }\end{array}$ & Phases present & Observed reaction \\
\hline $\mathrm{Hf} 88 \mathrm{~B} 12$ & $\alpha \mathrm{Hf}_{\mathrm{SS}}$ and $\mathrm{HfB}$ & $\mathrm{L} \Leftrightarrow \alpha \mathrm{Hf}_{\mathrm{SS}}+\mathrm{HfB}$ \\
$\mathrm{Hf77B} 23$ & $\alpha \mathrm{Hf}_{\mathrm{SS}}$ and $\mathrm{HfB}$ & $\mathrm{L} \Leftrightarrow \alpha \mathrm{Hf}_{\mathrm{SS}}+\mathrm{HfB}$ \\
$\mathrm{Hf75B} 25$ & $\alpha \mathrm{Hf}_{\mathrm{SS}}, \mathrm{HfB}$ and $\mathrm{HfB}_{2}$ & $\mathrm{~L}+\mathrm{HfB}_{2} \Leftrightarrow \mathrm{HfB}$ \\
Hf50B50 & $\alpha \mathrm{Hf}_{\mathrm{SS}}, \mathrm{HfB}$ and $\mathrm{HfB}_{2}$ & $\mathrm{~L}+\mathrm{HfB}_{2} \Leftrightarrow \mathrm{HfB}$ \\
$\mathrm{Hf} 33.4 \mathrm{~B} 66.6$ & $\alpha \mathrm{Hf}_{\mathrm{SS}}, \mathrm{HfB}$ and $\mathrm{HfB}_{2}$ & $\mathrm{~L} \Leftrightarrow \mathrm{HfB}_{2}$ \\
$\mathrm{Hf7.7B} 92.3$ & $\mathrm{HfB}_{2}$ and B-Rhom & $\mathrm{L} \Leftrightarrow \mathrm{HfB}_{2}+\mathrm{B}-\mathrm{Rhom}$ \\
Hf01B99 & $\mathrm{HfB}_{2}$ and B-Rhom & $\mathrm{L} \Leftrightarrow \mathrm{HfB}_{2}+\mathrm{B}-\mathrm{Rhom}$ \\
\hline
\end{tabular}

remaining region. Due to the small amount of $\mathrm{HfB}_{2}$ phase and a low contrast with respect to $\mathrm{HfB}$, it is not possible to point the $\mathrm{HfB}_{2}$ phase in the micrograph. On the other hand, the microstructure of the Hf50B50 alloy (Figure 3d) shows clearly the primary precipitation of $\mathrm{HfB}_{2}$, which is involved by $\mathrm{HfB}$, an evidence of the peritectic formation of $\mathrm{HfB}$, with a typical $\alpha \mathrm{Hf}_{\mathrm{sS}}+\mathrm{HfB}$ eutectic microstructure in the remaining region. The absence of $\mathrm{HfB}_{2}$ phase in the $\mathrm{Hf} 77 \mathrm{~B} 23$ alloy (Figure 2b) and its presence in the Hf75B25 alloy (Figure 2c) indicates that the transition from HfB primary to $\mathrm{HfB}_{2}$ primary should occur between 23 at. $\% \mathrm{~B}$ and 25 at. $\% \mathrm{~B}$, which correspond to the liquid composition of the peritectic reaction $\mathrm{L}+\mathrm{HfB}_{2} \Leftrightarrow \mathrm{HfB}$. This is in agreement with the proposal of Rudy and Windisch ${ }^{10}$ at approximately 24 at.\% B (Figure 1) and slightly in disagreement with the composition calculated by Rogl and Potter ${ }^{11}$ and Bitterman and $\operatorname{Rog} 1^{14}$, respectively, 22.5 at.\% B and 22 at.\% B.

The alloy with composition 66.6 at. $\% \mathrm{~B}$ intended to verify the composition of the liquid in the congruent transformation $\mathrm{L} \Leftrightarrow \mathrm{HfB}_{2}$, as proposed of Rudy and Windisch ${ }^{10}$. The diffractogram of the Hf33.4B66.6 alloy (Figure 2e) has indicated the presence of the $\mathrm{HfB}_{2}$ phase and minor amounts of $\alpha \mathrm{Hf}_{\mathrm{SS}}$ and HfB. In agreement with these

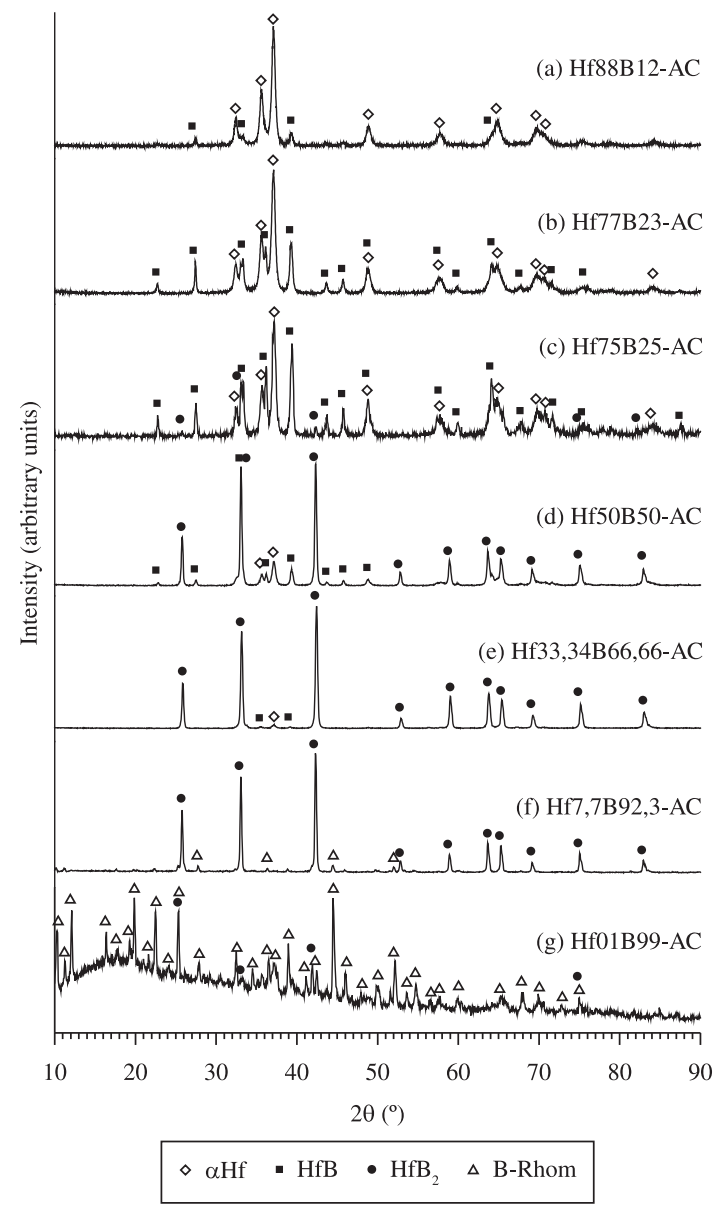

Figure 2. X-ray diffractograms of as-cast: a) Hf88B12; b) Hf77B23; c) Hf75B25; d) Hf50B50; e) Hf33,4B66,6; f) Hf7,7B92,3 and g) Hf01B99 alloys. 


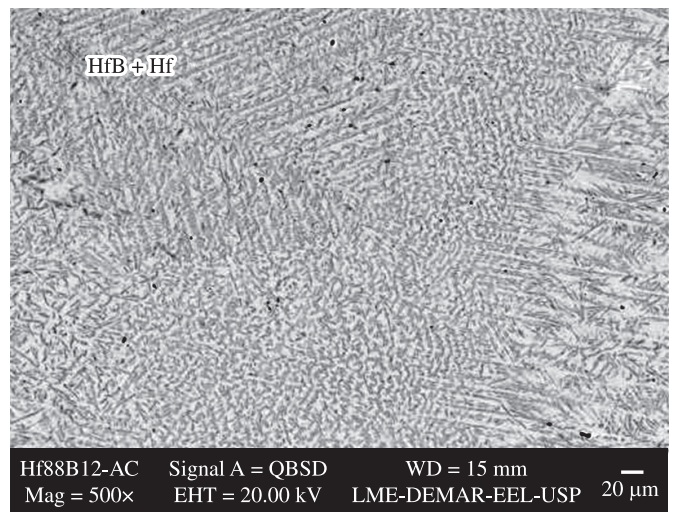

(a)

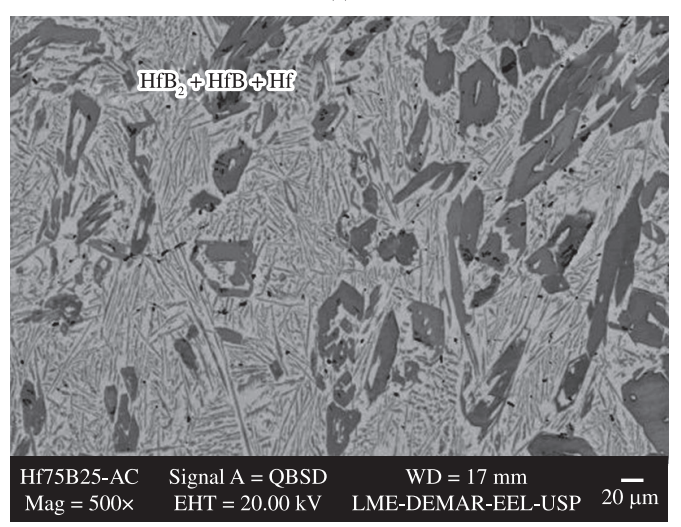

(c)

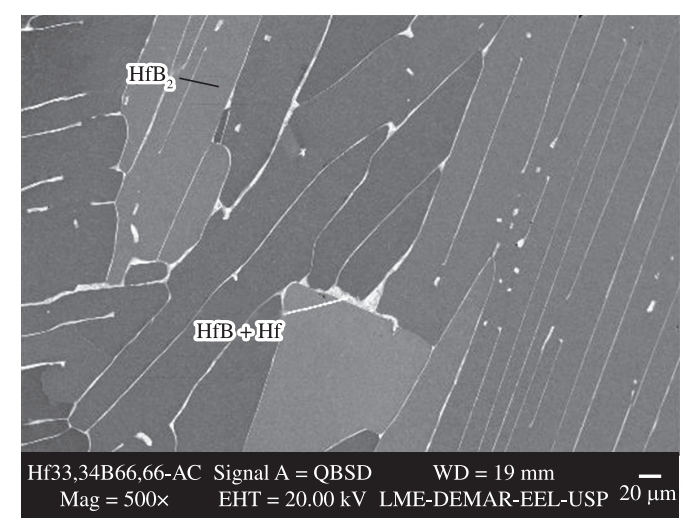

(e)

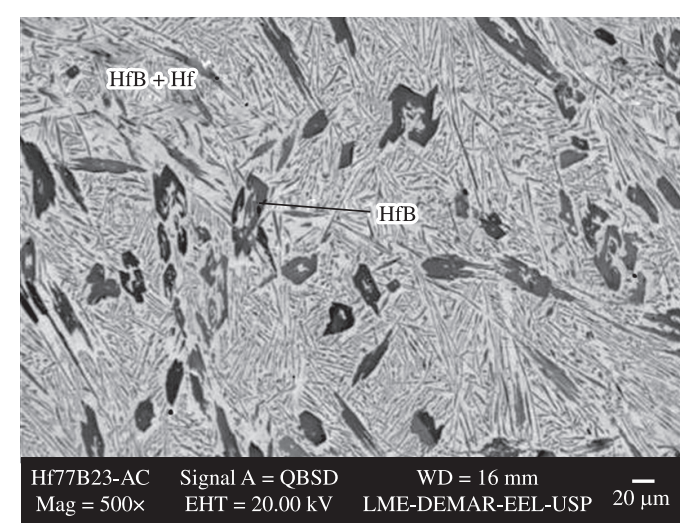

(b)

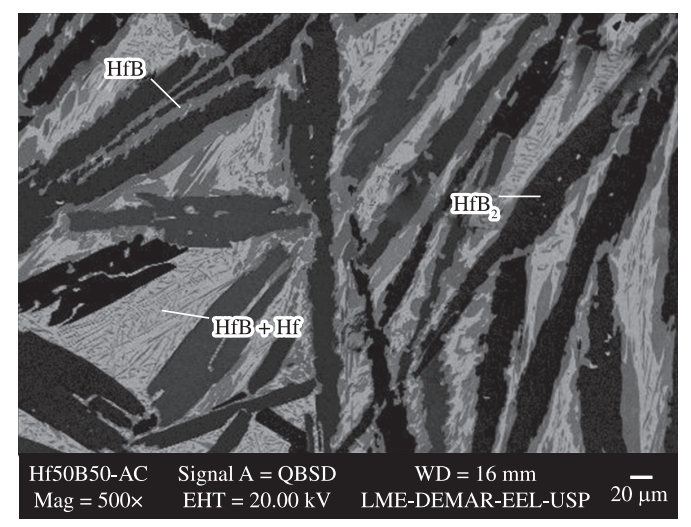

(d)

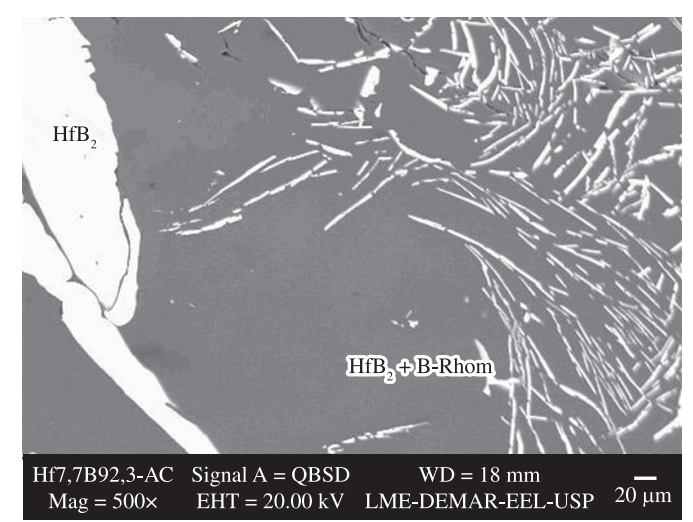

(f)

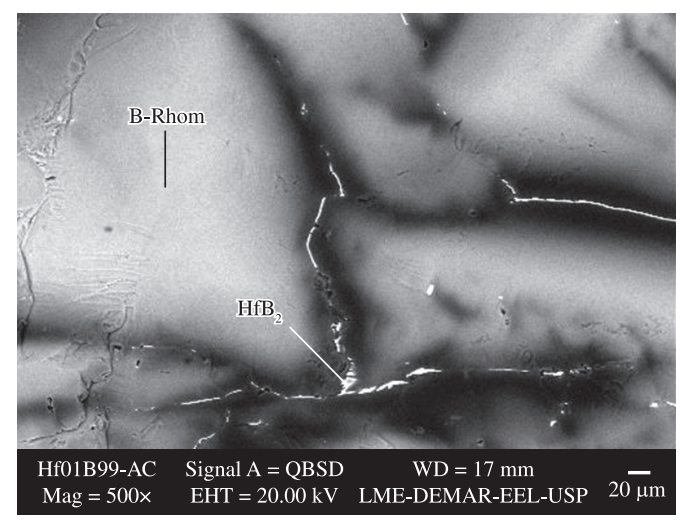

(g)

Figure 3. Micrographs of as-cast: a) Hf88B12; b) Hf77B23; c) Hf75B25; d) Hf50B50; e) Hf33,4B66,6; f) Hf7,7B92,3 and g) Hf01B99 alloys. 
results, the microstructure of this alloy (Figure 3e) shows large amount of primary $\mathrm{HfB}_{2}$, the $\alpha \mathrm{Hf}_{\mathrm{sS}}$ and $\mathrm{HfB}$ phases being present in the last regions to solidify. In addition, these results confirm the congruent formation of $\mathrm{HfB}_{2}$ as considered for Rudy and Windisch ${ }^{10}$ (Figure 1), Rogl and Potter ${ }^{11}$ and Bitterman and Rogl $1^{14}$.

The alloys with compositions between 70 at.\% B and 100 at. $\% \mathrm{~B}$ intended to verify the composition of the liquid in the eutectic transformation $\mathrm{L}^{\rightleftarrows} \mathrm{HfB}_{2}+\mathrm{B}-\mathrm{Rhom}_{\mathrm{SS}}$, as proposed of Rudy and Windisch ${ }^{10}$. The diffractograms of the Hf7.7B92.3 alloy (Figure 2f) and Hf01B99 alloy (Figure 2g) have indicated the presence of $\mathrm{HfB}_{2}$ and $\mathrm{B}-\mathrm{Rhom}_{\mathrm{SS}}$ phases. In the microstructure of the Hf7.7B92.3 alloy (Figure 3f), primary precipitation of $\mathrm{HfB}_{2}$ is observed with a typical $\mathrm{HfB}_{2}+\mathrm{B}-\mathrm{Rhom}_{\mathrm{SS}}$ eutectic microstructure in the remaining region. On the other hand, the Hf01B99 alloy (Figure 3g) presents a large amount of primary B-Rhom ${ }_{\text {ss }}$ phase, and the presence of the $\mathrm{HfB}_{2}$ phase in the last parts to solidify, possibly formed by the $\mathrm{HfB}_{2}+\mathrm{B}-\mathrm{Rhom}_{\mathrm{sS}}$ eutectic. These results indicate that the liquid composition of the $\mathrm{L} \mathrm{HfB}_{2}+\mathrm{B}-\mathrm{Rhom}_{\mathrm{SS}}$ eutectic reaction should be around 99

\section{References}

1. Jackson MR, Bewlay BP, Rowe RG, Skelly DW and Lipsitt HA. A high-temperature refractory metal-intermetallic composites. Journal of Metals. 1996; 48:39-43.

2. Subramanian PR, Mendiratta MG and Dimiduk DM. The Development of Nb-Based Advanced Intermetallic Alloys for Structural Applications. Journal of Metals. 1996; 48:33-38.

3. Shah DM, Anton DL, Chin S and Pope DP. In-situ refractory intermetallic-based composites. Materials Science and Engineering. 1995; 192-193:658-672. http://dx.doi. org/10.1016/0921-5093(95)03318-1

4. Bewlay BP, Jackson MR, Zhao J-C and Subramanian PR. A rewiew of very-high-temperature $\mathrm{Nb}$-silicide-based composites. Metallurgical and Materials Transactions A. 2003;34A:2043-52. http://dx.doi.org/10.1007/s11661-003-0269-8

5. Zhao J-C and Westbrook JH. Ultrahigh-temperature materials for jet engines. MRS Bullettin. 2003; 622-30.

6. Ward-Close CM, Minor R and Doorbar PJ. Intermetallic-matrix composites - A Review. Intermetallics. 1996; 4:217-219. http:// dx.doi.org/10.1016/0966-9795(95)00037-2

7. Ferreira F. Thermodynamic modeling of the systems Nb-Si-B and $\mathrm{Mo}-\mathrm{Si}-\mathrm{B}$. [Tese]. Lorena: Faculdade de Engenharia Química de Lorena; 2003.

8. Lima BB. Experimental determination of the isothermal section $1600^{\circ} \mathrm{C}$ and the Liquidus Projection in the rich region in $V$ of the $V$-Si-B system. [Tese]. Lorena: Faculdade de Engenharia Química de Lorena; 2004.

9. Fernandes PB. Experimental evaluation and thermodynamic modeling of the system Ta-Si-B in the rich region in tantalum. [Tese]. Lorena: Escola de Engenharia Química de Lorena; 2009.

10. Rudy E and Windisch S. Ternary Phase Equilibria in Transition Metal-Boron-Carbon-Silicon Systems. Technical Report, AFML-TR-62-2. Ohio: Air Force Materials Lab, WrightPatterson AFB; 1969. v. 4, 689 p.

11. Rogl P and Potter PE. A Critical Rewiew and Thermodynamic Calculation of the Binary System HafniumBoron. CALPHAD. 1988; 12(3):207-218. http://dx.doi. org/10.1016/0364-5916(88)90001-6 at. $\%$ B, as proposed by Rudy and Windisch ${ }^{10}$, Figure 1, and Bitterman and $\operatorname{Rog} 11^{14}$, but slightly in disagreement with the composition calculated by Rogl and Potter $^{11}$ at 97.3 at.\% B.

\section{Conclusions}

In this investigation we have carried out a detailed microstructural characterization of as-cast Hf-B alloys which allowed the evaluation of the invariant reactions involving the liquid phase in this system. The phases identified are $\alpha \mathrm{Hf}_{\mathrm{SS}}$ and B-Rhom ${ }_{\mathrm{SS}}$, the intermediate HfB and $\mathrm{HfB}_{2}$ compounds and the liquid $\mathrm{L}$. The reactions are the eutectic $\mathrm{L} \Leftrightarrow \alpha \mathrm{Hf}_{\mathrm{SS}}+\mathrm{HfB}$ and $\mathrm{L} \Leftrightarrow \mathrm{HfB}_{2}+\mathrm{B}-\mathrm{Rhom}_{\mathrm{ss}}$, the peritectic $\mathrm{L}+\mathrm{HfB}_{2} \Leftrightarrow \mathrm{HfB}$ and the congruent formation of $\mathrm{HfB}_{2}$. In general, a good agreement was found between our data and those of the currently accepted Hf-B phase diagram as proposed by Rudy and Windisch ${ }^{10}$.

\section{Acknowledgements}

The authors acknowledge FAPESP through grant 2007/05206-5.

12. Portnoi KI and Romashov VM. Binary Constituition Diagrams of System Composed of Various Elements and Boron. Poroshkovaya Metallurgiya. 1972; 113(5):48-56.

13. Portnoi KI, Romashov VM, Romanovich IV, Levinskii Yu V, Prokofev SA. Phase Diagram of the Hafnium-Boron system. Inorganic Materials, translated from Izvestiya Akademii Nauk SSSR. Neorganicheskie Materialy. 1971; 7:1769-1772.

14. Bitterman H and Rogl P. On the Ternary System Hafnium-BoronCarbon. Journal of Solid State Chemistry. 2000; 154:257-262.

15. Kraus W and Nolze G. PowderCell for Windows. version 2.3. Berlim: Federal Institute for Materials research and testing; 1999.

16. Ross RG and Hume-Rothery W. High Temperature X-Ray Metallography - III Applications to the Study of Chromium, Hafnium, Molybdenum, Rhodium, Ruthenium and Tungsten. Journal of the Less-Common Metals. 1963; 5:258-270. http:// dx.doi.org/10.1016/0022-5088(63)90031-6

17. Vilars P. Pearson's handbook of crystallographic data for intermetallic phases. 2th ed. ASM International; 1991.

18. Romans PA, Paashe OG and Kato H. The Transformation Temperature of Hafnium. Journal of the Less-Common Metals. 1965; 8:213-215. http://dx.doi.org/10.1016/00225088(65)90048-2

19. Rudy E and Windisch S. Ternary Phase Equilibria in Transition Metal-Boron-Carbon-Silicon Systems, Compendium of Phase Diagram Data, part. I, vol. IX, AFML-TR-65-2. Ohio: Air Force Materials Lab, Wright-Patterson AFB; 1966. p. 1-42.

20. Kugai LN. Chemical Stability of Borides of Transition Metals of Groups IV-VI in Alkaline Solutions. Inorganic Materials, translated from Izvestiya Akademii Nauk SSSR. Neorganicheskie Materialy. 1972; 8(4):669-670.

21. Anderson $\mathrm{S}$ and Lundström T. The Solubility of Chromium in b-Rhombohedral Boron as Determined in $\mathrm{CrB} \sim 41$ System by Single-Crystal Diffractometry. Journal of Solid State Chemistry. 1970; 2:603-611. http://dx.doi.org/10.1016/00224596(70)90057-5 